NOTE

Eda Suer $\cdot$ Suha Sayrac $\cdot$ Elif Sarinay

Hakan Emre Ozturk • Mustafa Turkoz • Akitoyo Ichinose

Tsuyoshi Nagatake $\cdot$ Kamruddin Ahmed

\title{
Variation in the attachment of Streptococcus pneumoniae to human pharyngeal epithelial cells after treatment with S-carboxymethylcysteine
}

Received: January 21, 2008 / Accepted: May 22, 2008

\begin{abstract}
S-carboxymethylcysteine (S-CMC) is a mucolytic agent that can prevent respiratory infection by decreasing the attachment of respiratory pathogens to human pharyngeal epithelial cells (HPECs). Streptococcus pneumoniae is a major cause of respiratory infections. A previous study revealed that treatment of $S$. pneumoniae with S-CMC caused a decrease in the attachment of this bacterium to HPECs. In the present study we found that the effect of S-CMC varied according to hosts and strains. S-CMC treatment altered the surface structure of S. pneumoniae, resulting in a decrease of attachment, without affecting the virulence of the bacteria.
\end{abstract}

Key words Streptococcus pneumoniae - S-carboxymethylcysteine $\cdot$ Epithelial cells $\cdot$ Human

Streptococcus pneumoniae is a major pathogen in respiratory infections. Worldwide, the rise of antibiotic resistance to $S$. pneumoniae has made it difficult to treat $S$. pneumoniae infections with commonly used antibiotics. ${ }^{1}$ Therefore, focus has been placed on the search for novel means of treatment which might avoid the risk of developing antibiotic resistance. S-carboxymethylcysteine (S-CMC) is a nonantibiotic drug which has the potential to be used to prevent respiratory infection. ${ }^{2} \mathrm{~S}-\mathrm{CMC}$ is a mucolytic agent

E. Suer $\cdot$ S. Sayrac $\cdot$ E. Sarinay $\cdot$ H.E. Ozturk $\cdot$ M. Turkoz

K. Ahmed ${ }^{1}(\square)$

Department of Molecular Biology and Genetics, Bilkent University,

Ankara, Turkey

A. Ichinose $\cdot$ T. Nagatake

Laboratory for Electron Microscopy and Department of Internal

Medicine, Institute of Tropical Medicine, Nagasaki University,

Nagasaki, Japan

Present address:

${ }^{1}$ Division of Infectious Diseases, Department of Social and Environmental Medicine, Institute of Scientific Research, Oita University, 1-1 Idaigaoka, Hasama-machi, Yufu, Oita 879-5593, Japan

Tel. +81-97-586-5798; Fax +81-97-586-5719

e-mail: ahmed@med.oita-u.ac.jp that is used in the treatment of different respiratory diseases characterized by abnormal mucus secretion. Noguchi ${ }^{3}$ initially demonstrated in clinical studies that the administration of S-CMC decreased the number of episodes of recurrent respiratory tract infections. Subsequently other studies showed its effectiveness in respiratory conditions as well as ear diseases. ${ }^{2,45} \mathrm{~A}$ series of studies demonstrated that S-CMC was able to decrease significantly the attachment of major respiratory bacteria such as Haemophilus influenzae, S. pneumoniae, and Moraxella catarrhalis to human pharyngeal epithelial cells (HPECs). ${ }^{6-8}$ This decrease in bacterial attachment results in a decrease in the occurrence of respiratory infections, because the attachment of bacteria to the host cell is responsible for the pathogenesis of respiratory infections. The decrease of attachment is explained by the fact that S-CMC can deplete carbohydrate structures on the cell surface and it can also alter the surface charge of cells. ${ }^{6,7}$

Although treatment of M. catarrhalis and non-typable $H$. influenzae with S-CMC has no effect on their attachment to HPECs, treatment of $S$. pneumoniae with this agent causes a significant decrease in attachment ability, as shown in a study reported by Cakan at al. ${ }^{8}$ The mechanism of this effect is unknown. In the study of Cakan et al., ${ }^{8}$ cells from one subject were used. Therefore, in the present study, we expanded our research to find out whether this phenomenon is affected by interindividual or interstrain variations. We found that there was interindividual or interstrain variation in the attachment inhibition exerted by S-CMC. In the present study we also tried to explore the possible mechanism by which S-CMC can cause attachment inhibition. We found that attachment inhibition seemed to occur due to changes in the bacterial surface structure after treatment with S-CMC; however the inhibition of attachment did not alter the virulence of the bacteria.

The following strains of $S$. pneumoniae were used for attachment inhibition assays: strain SP-95-203 (minimum inhibitory concentration [MIC]: benzylpenicillin [PCG] $0.05 \mu \mathrm{g} / \mathrm{ml}$ ) of serotype 3; strain SP-02-26 (MIC: PCG $1 \mu \mathrm{g} /$ $\mathrm{ml}$, mentioned previously as strain $\mathrm{Y}-21$ ) of serotype $23 \mathrm{~F}$ (originally isolated from a patient in Spain thought to be 
responsible for the spread of penicillin-resistance in different parts of the world), ${ }^{9}$ strain SP-01-291 (MIC: PCG $16 \mu \mathrm{g} /$ $\mathrm{ml}$ ), and strain SP-01-292 (MIC: PCG $4 \mu \mathrm{g} / \mathrm{ml}$ ) of serotype 19F. All strains were isolated from the sputum of patients with respiratory infections. HPECs were obtained from three healthy volunteers; two females (subjects 2 and 3 ) and one male (subject 1 ) with an average age of 19 years. The attachment inhibition assay was performed as previously described. ${ }^{8}$ In the present study, 5\% sheep blood agar (Columbia agar $+5 \%$ sheep blood; Biomerieux, Marcy l'Etoile, France) was used to grow S. pneumoniae. Bacteria and HPECs were treated with $10 \mu \mathrm{g} / \mathrm{ml}$ and $1 \mu \mathrm{g} / \mathrm{ml}$ of SCMC (Kyorin Pharmaceutical, Tokyo, Japan), respectively, and suspended in $1 / 15 \mathrm{mmol}$ phosphate buffer $(\mathrm{pH}$ 7.2) for $30 \mathrm{~min}$ at $37^{\circ} \mathrm{C}$. In a previous study, it was reported that the peak serum level of S-CMC was $2.4-4.6 \mu \mathrm{g} / \mathrm{ml}$, and this occurred $1.5-3.5 \mathrm{~h}$ after the oral administration of $500 \mathrm{mg}$ S-CMC. ${ }^{6}$ In another study, after the oral administration of $500 \mathrm{mg}$ S-CMC three times daily for 7 days, the sputum level of S-CMC ranged from less than 0.1 to $2.0 \mu \mathrm{g} / \mathrm{ml}$. Although these concentrations are compatible with using $1 \mu \mathrm{g} / \mathrm{ml}$ of S-CMC, we took other factors into consideration to decide the concentration of S-CMC to be used in the present study. If S-CMC is used as an attachment inhibition agent it is not given orally but is delivered directly to the pharynx by spray or gargle; therefore, a higher drug concentration can be administered. We analyzed the data of our previous experiments and found that 10 and $1 \mu \mathrm{g} / \mathrm{ml}$ were the minimum concentrations at which attachment inhibition occurred in a consistent and significant way, for bacteria and HPECs, respectively. ${ }^{6-8}$ As controls, untreated bacteria and HPECs were handled similarly to the treated bacteria and HPECs, without treatment with SCMC. The mean value of duplicate experiments was determined in each experiment. At least three experiments were done for each subject or strain. Compared with the control, a $50 \%$ decrease in mean bacterial attachment was considered as significant. ${ }^{10}$ Our experiment showed that, compared to the untreated control, there was no significant change in the viability of $S$. pneumoniae after treatment with S-CMC. Gram staining showed that there was no significant change in S-CMC-treated bacteria compared with the control.

To determine the effect of S-CMC on the surface morphology of S. pneumoniae, electron microscopy was done after treating strain SP-95- $19^{8}$ with 10 and $100 \mu \mathrm{g} / \mathrm{ml}$ of S$\mathrm{CMC}$ for $30 \mathrm{~min}$ in a shaking water bath at $37^{\circ} \mathrm{C}$. Our previous study showed that the changes that occur at these concentrations are suitable for observation by electron microscope. ${ }^{6}$ Similarly handled untreated bacteria were taken as controls. Bacteria were washed with $0.1 \mathrm{M}$ cacodylate buffer containing $0.04 \%$ ruthenium red (RR). Then they were fixed with $2 \%$ glutaraldehyde in $0.1 \mathrm{M}$ cacodylate buffer containing $0.05 \% \mathrm{RR}$ overnight. After post-fixation with osmium tetroxide, the samples were embedded in Quetol 653 (Nishshin EM, Tokyo, Japan) according to a previously published report. ${ }^{11}$

The effects of S-CMC on bacterial virulence were validated by challenging mice with $S$. pneumoniae. Five-week-

\section{Attachment assay: S. pneumoniae treated with S- CMC}

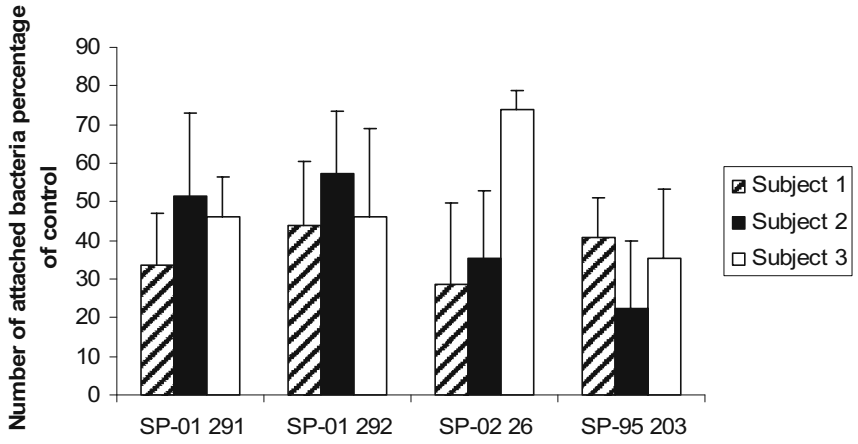

Fig. 1. Results of attachment inhibition assay after strains of Streptococcus pneumoniae were treated with $10 \mu \mathrm{g} / \mathrm{ml}$ of S-carboxymethylcysteine $(S-C M C)$. The names of the strains of $S$. pneumoniae are shown on the $X$-axis. The $Y$-axis indicates the attachment of bacteria per number of epithelial cells, expressed as percentages of the respective controls. In each experiment, the attachment assay was done in duplicate and three experiments were done to determine the attachment of bacteria. Striped bars, Subject 1; black bars, subject 2; white bars, subject 3

old pathogen-free, female ICR mice (Shizuoka Agricultural Cooperation Association for Laboratory Animals, Shizuoka, Japan) were used. The mice were housed in clean conditions and were given sterile food and water. The mice were anesthetized by chloroform inhalation. Groups of five mice were challenged intraperitoneally with S-CMC $(10 \mu \mathrm{g} /$ $\mathrm{ml}$ )-treated bacterial suspensions in sterile phosphatebuffered saline (PBS), with a concentration of $5 \times 10^{7} \mathrm{cfu} / \mathrm{ml}$ in an inoculum volume of $0.5 \mathrm{ml}$. Control mice were challenged with bacteria not treated with S-CMC. Mortality was determined every $24 \mathrm{~h}$.

The attachment inhibition assay after bacteria were treated with S-CMC (Fig. 1) showed that, in subject 1, the attachment (expressed as percentage of the control [mean \pm SD]) of strains SP-01-291, SP-01-292, SP-02-26, and SP$95-203$ was $33.7 \pm 13.3 \%, 44.1 \pm 16.3 \%, 28.6 \pm 21.1 \%$, and $40.9 \pm 10.1 \%$, respectively. In subject 2 , the attachment of strains SP-01-291, SP-01-292, SP-02-26, and SP-95-203 was $51.4 \pm 21.7 \%, 57.1 \pm 16.4 \%, 35.5 \pm 17.3 \%$, and $22.4 \pm 17.3 \%$ of the control, respectively. In subject 3 , the attachment of strains SP-01-291, SP-01-292, SP-02-26, and SP-95-203 was $45.9 \pm 10.6 \%, 46.1 \pm 23.1 \%, 73.8 \pm 5.1 \%$, and $35.2 \pm 18.2 \%$ of the control, respectively.

Except for SP-01-291 and SP-01-292 with the HPECs from subject 2 and SP-02-26 with the HPECs from subject 3 , all experiments showed there was a significant decrease of attachment after the $S$. pneumoniae were treated with S-CMC. The attachment inhibition assay after HPECs were treated with S-CMC (Fig. 2) showed that in subject 1, the attachment of strains, SP-01-291, SP-01-292, SP-02-26, and SP-95-203 was $23.8 \pm 23.1 \%, 13.4 \pm 8.6 \%, 25.8 \pm 9.2 \%$, and $22.0 \pm 33.7 \%$ of the control, respectively. In subject 2 , the attachment of strains SP-01-291, SP-01-292, SP-02-26, and SP-95-203 was $52.3 \pm 36.2 \%, 32.8 \pm 18.2 \%, 31.4 \pm 24.9 \%$, and $29.7 \pm 10.2 \%$ of the control, respectively. In subject 3, the attachment of strains SP-01-291, SP-01-292, SP-02-26, 
Attachment assay: HPECs treated with S-CMC


Fig. 2. Results of attachment inhibition assay after human pharyngeal epithelial cells (HPECs) were treated with $1 \mu \mathrm{g} / \mathrm{ml}$ of S-CMC. The names of the strains of $S$. pneumoniae are shown on the $X$-axis. The $Y$-axis indicates the attachment of bacteria per numbers of epithelial cells expressed as percentages of the respective controls. In each experiment, the attachment assay was done in duplicate and three experiments were done to determine the attachment of bacteria. Striped bars, Subject 1; black bars, subject 2; white bars, subject 3

and SP-95-203 was $26.6 \pm 15.0 \%, 25.0 \pm 31.2 \%, 32.1 \pm 40.4 \%$, and $82.9 \pm 77.6 \%$ of the control, respectively. Except for SP-01-291 with the HPECs from subject 2 and SP-95-203 with the HPECs from subject 3 , all experiments showed a significant decrease of bacterial attachment to the HPECs. The attachment of $S$. pneumoniae to HPECs treated with S-CMC showed a greater decrease compared with the results of the attachment inhibition assay of bacteria treated with S-CMC (Fig. 1). The differences found in each experiment after S-CMC treatment were due to interstrain and intersubject variations in the expression of adhesins and receptors on bacteria and HPECs, respectively.

As observed by electron microscopy, the surface in the untreated control bacteria appeared to be smooth (Fig. 3a). On the other hand, the surface became electron-dense after treatment with $10 \mu \mathrm{g} / \mathrm{ml}$ of S-CMC (Fig. 3b). This change was more evident in bacteria treated with $100 \mu \mathrm{g} / \mathrm{ml}$ of SCMC (Fig. 3c).

The virulence test showed that all mice died within $24 \mathrm{~h}$ and, therefore, compared to the untreated control, there was no change of virulence of $S$. pneumoniae, although the attachment to the cells was decreased after treatment with S-CMC.

The adherence of $S$. pneumoniae to eukaryotic cells is the initial step in the colonization and infection of the host. ${ }^{12}$ Cell-wall proteins such as choline-binding proteins and peptide permeases have been reported to act as adhesins. ${ }^{13-15}$ The bacterial capsule may function as an adhesin and enhance pneumococcal colonization ${ }^{16,17}$ S. pneumoniae is capable of expressing a repertoire of at least 90 unique capsular polysaccharide types. ${ }^{18}$ Each of these polysaccharides differs in the composition and linkage of its component sugars as well as other substitutes. ${ }^{17}$ Other than these structures, surface charge also influences the attachment of bacteria to host epithelial cells.

The present study showed that S-CMC was able to inhibit the attachment of different strains of $S$. pneumoniae to HPECs from different individuals. However, the decrease

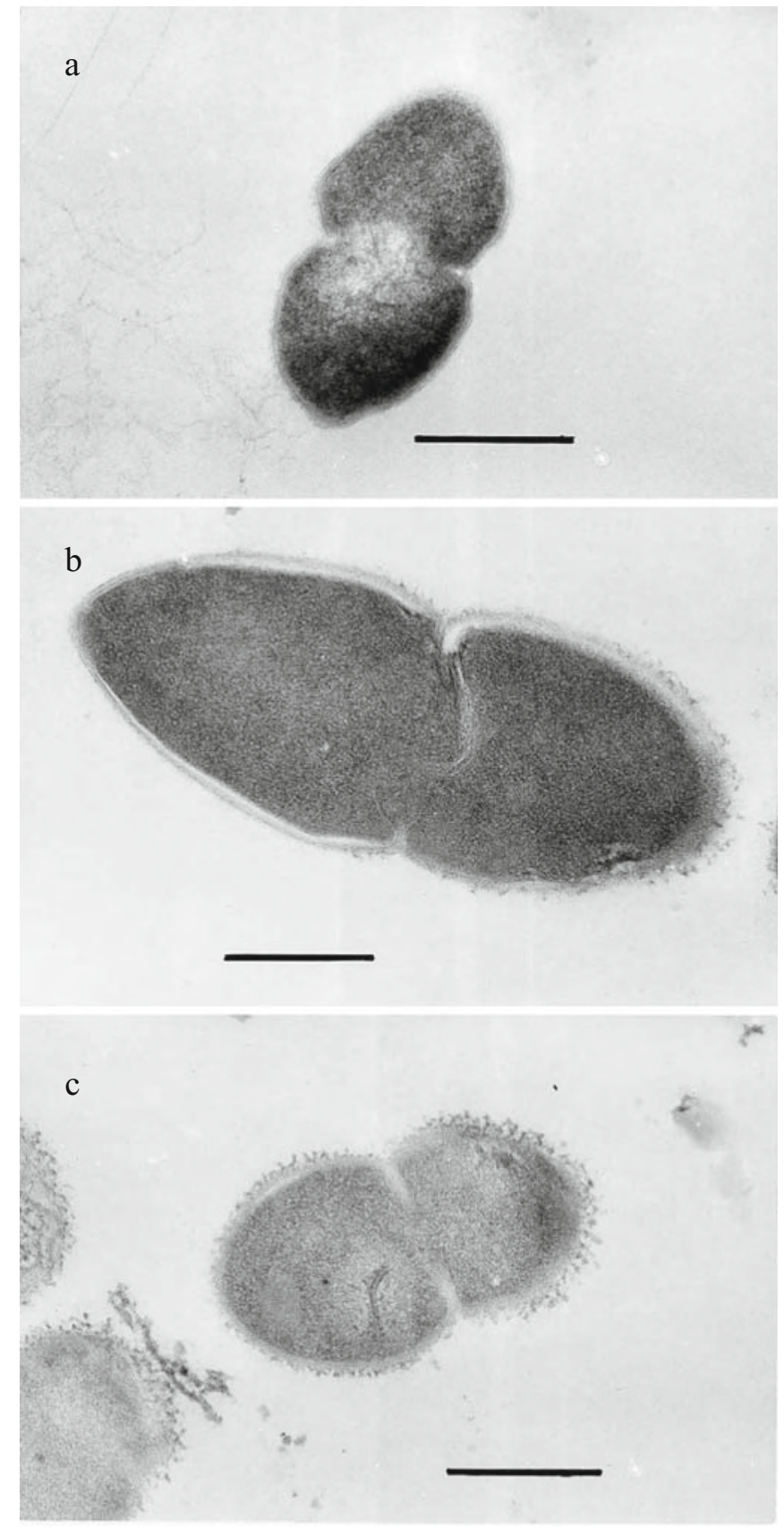

Fig. 3a-c. Transmission electron microscope photographs of $S$. pneumoniae, showing the difference between bacteria treated with S-CMC and the untreated control. a In the untreated control, $S$. pneumoniae is observed to have a smooth surface. After treatment with S-CMC (b, c), the bacterial surface showed a granular structure, which was more apparent after treatment with $100 \mu \mathrm{g} / \mathrm{ml}$ of S-CMC (c) than after treatment with $10 \mu \mathrm{g} / \mathrm{ml}$ of this agent (b). Bars, $400 \mathrm{~nm}$

of attachment was not significant in all cases. Therefore, it appears that strains of S. pneumoniae may differ in their attachment abilities and may respond differently to attachment-modulating agents. This study revealed that there were changes on the surface of $S$. pneumoniae after treatment with S-CMC. However, further study should be done to confirm the electron-dense particles seen on the surface of S. pneumoniae after treatment with S-CMC. 
Of note, the changes on the surface of S. pneumoniae did not affect the virulence of the bacteria, as revealed by the mouse experiment. Thus, the virulence test in mice added further knowledge regarding the mechanism of action of $\mathrm{S}-\mathrm{CMC}$ in vivo. The decrease of attachment after S-CMC treatment was not due to bactericidal effects, as our quantitative culture assay showed that S-CMC had no effect on the viability of the bacteria. This confirms the results of our previous study. ${ }^{8}$ There is a range of interindividual variation in patients treated with S-CMC. ${ }^{19}$ Metabolism was implicated as a major factor influencing the efficacy of S-CMC. The present study has clarified other important factors that may influence the efficacy of S-CMC, such as the characteristics of the bacterial and host cells which express different surface components.

Acknowledgments Part of this project was supported by Kyorin Pharmaceutical Co. Ltd., Tokyo, Japan.

\section{References}

1. Felmingham D, Canton R, Jenkins SG. Regional trends in betalactam, macrolide, fluoroquinolone and telithromycin resistance among Streptococcus pneumoniae isolates 2001-2004. J Infect 2007;55:111-8.

2. Yasuda H, Yamaya M, Sasaki T, Inoue D, Nakayama K, Tomita $\mathrm{N}$, et al. Carbocysteine reduces frequency of common colds and exacerbations in patients with chronic obstructive pulmonary disease. J Am Geriatr Soc 2006;54:378-80.

3. Noguchi Y. Effects of carbocysteine on the prevention of chronic respiratory infection (in Japanese). Jpn Med Consultant New Remedies 1989;26:1608-13.

4. Allegra L, Cordaro CI, Grassi C. Prevention of acute exacerbations of chronic obstructive bronchitis with carbocysteine lysine salt monohydrate: a multicenter, double-blind, placebo-controlled trial. Respiration 1996;63:174-80.

5. Moore RA, Commins D, Bates G, Phillips CJ. S-carboxymethylcysteine in the treatment of glue ear: quantitative systematic review. BMC Fam Pract 2001;2:3.
6. Zheng $\mathrm{CH}$, Ahmed K, Rikitomi N, Martinez G, Nagatake T. The effects of S-carboxymethylcysteine and $\mathrm{N}$-acetylcysteine on the adherence of Moraxella catarrhalis to human pharyngeal epithelial cells. Microbiol Immunol 1999;43:107-13.

7. Ndour CT, Ahmed K, Nakagawa T, Nakano Y, Ichinose A, Tarhan G, et al. Modulating effects of mucoregulating drugs on the attachment of Haemophilus influenzae. Microb Pathog 2001;30: 121-7.

8. Cakan G, Turkoz M, Turan T, Ahmed K, Nagatake T. Scarboxymethylcysteine inhibits the attachment of Streptococcus pneumoniae to human pharyngeal epithelial cells. Microb Pathog 2003;34:261-5.

9. Ahmed K, Martinez G, Wilson S, Yoshida R, Dhar R, Mokaddas $\mathrm{E}$, et al. The prevalence and clonal diversity of penicillin-resistant Streptococcus pneumoniae in Kuwait. Epidemol Infect 2000;125: 573-81.

10. Simon PM, Goode PL, Mobasseri A, Zopf D. Inhibition of Helicobacter pylori binding to gastrointestinal epithelial cells by sialic acid-containing oligosaccharides. Infect Immun 1997;65:750-7.

11. Kushida H. A new method for embedding with low viscosity epoxy resin "Quetol 653". J Electron Microsc (Tokyo). 1974;29:197.

12. Adamou JE, Wizemann TM, Barren P, Langermann S. Adherence of Streptococcus pneumoniae to human bronchial epithelial cells (BEAS-2B). Infect Immun 1998;66:820-2.

13. Gosink KK, Mann ER, Guglielmo C, Toumanen EI, Masure HR. Role of novel choline binding proteins in virulence of Streptococcus pneumoniae. Infect Immun 2000;68:5690-5.

14. Yother J, White JM. Novel surface attachment mechanism of the Streptococcus pneumoniae protein PspA. J Bacteriol 1994;176: 2976-85.

15. Cundell DR, Pearce BJ, Sandros J, Naughton AM, Masure HR. Peptide permeases from Streptococcus pneumoniae affect adherence to eukaryotic cells. Infect Immun 1995;63:2493-8.

16. Lopez R. Pneumococcus: the sugar-coated bacteria. Int Microbiol 2006;9:179-90.

17. Nelson AL, Roche AM, Gould JM, Chim K, Ratner AJ, Weiser JN. Capsule enhances pneumococcal colonization by limiting mucus-mediated clearance. Infect Immun 2007;75:83-90.

18. Henrichsen J. Six newly recognized types of Streptococcus pneumoniae. J Clin Microbiol 1995;33:2759-62.

19. Mitchell SC, Steventon GB. Carbocysteine therapy in older people with chronic obstructive pulmonary disease. J Am Geriatr Soc 2006;54:1792-3. 